\title{
PROFIL KETERAMPILAN PROSES SAINS MAHASISWA MELALUI IMPLEMENTASI SPADA UNRAM
}

\section{PROFILE OF STUDENT SCIENCE PROCESS SKILLS THROUGH THE IMPLEMENTATION OF SPADA UNRAM}

\author{
Muhammad Syazali*, Aisa Nikmah Rahmatih, dan Nursaptini \\ Program Studi PGSD FKIP Universitas Mataram, Mataram, Indonesia \\ *Email: $\underline{\text { m.syazali@unram.ac.id }}$
}

Diterima: 19 Desemmber 2020. Disetujui: 3 Januari 2021. Dipublikasikan: 13 Januari 2021

\begin{abstract}
Abstrak: Pandemi Covid-19 menyebabkan pembelajaran dilakukan secara jarak jauh atau daring. Di Universitas Mataram, pembelajaran secara daring terfasilitasi melalui SPADA Unram. Oleh karena implementasinya yang tergolong baru, maka perlu diketahui efeknya terhadap capaian tujuan pembelajaran yang menjadi kompetensi minimal dapat dikuasai oleh mahasiswa. Pada studi ini, kami mengkaji keterampilan proses sains mahasiswa. Penelitian dilakukan pada mahasiswa semester 5 yang memprogramkan matakuliah Ilmu Alamiah Dasar (IAD). Sampel berjumlah 35 mahasiswa yang ditentukan secara purposive. Data keterampilan proses sains mahasiswa dikumpulkan menggunakan instrumen tes yang sudah divalidasi ahli. Item berjumlah 6 soal subjektif yang disesuaikan dengan jumlah indikator keterampilan proses sains (KPS) dasar yaitu observing, classification, measuring, communicating, predicting, dan infering. Tes dilakukan sebanyak dua kali yaitu melalui kuis 1 topik Pengantar IAD, dan kuis 2 topik Materi dan Energi. Analisis data keterampilan proses sains mahasiswa menggunakan statistik deskriptif dan inferensial dengan mengukur rata-rata (mean), persentase, dan uji komparasi. Kami menemukan bahwa rata-rata derajat penguasaan (DP) mahasiswa terhadap KPS dasar berada pada kategori sangat kurang. Proporsi mahasiswa dengan kategori baik dan cukup hanya $11.43 \%$ pada kuis pertama, dan pada kuis kedua hanya $2.86 \%$ kategori baik dan $8.57 \%$ kategori cukup. Hasil uji komparasi menunjukkan bahwa tidak ada perbedaan DP KPS dasar yang signifikan antara kuis 1 dan kuis 2 . Kondisi ini mengindikasikan bahwa perlu adanya inovasi yang dapat memberikan pengalaman belajar lebih baik dan dapat meningkatkan KPS dasar mahasiswa.
\end{abstract}

Kata Kunci: Derajat penguasaan, Ilmu Alamiah Dasar, keterampilan proses sains

\begin{abstract}
The Covid-19 pandemic has caused learning to be carried out remotely or online. At the Universitas Mataram, online learning is facilitated through SPADA Unram. Because the implementation is relatively new, it is necessary to know the effect on the achievement of learning objectives which are the minimum competencies that can be mastered by students. In this study, we examined students' science process skills. The research was conducted on $5^{\text {th }}$ semester students programming the Basic Natural Science (BNS) course. The sample consisted of 35 students who were determined purposively. Student science process skills data were collected using test instruments that have been validated by experts. Items totaling 6 subjective questions adjusted to the number of indicators of basic science process skills (SPS), namely observing, classification, measuring, communicating, predicting, and inferring. The test was conducted twice, namely through the first kuis topic Introduction to BNS, and second kuis topic Material and Energy. Data analysis of student science process skills using descriptive and inferential statistics by measuring the mean, percentage, and comparative tests. We found that the average degree of mastery (DM) of students towards basic SPS was in the very poor category. The proportion of students with good and sufficient categories was only $11.43 \%$ in the first kuis, and in the second kuis only $2.86 \%$ in good categories and $8.57 \%$ inadequate categories. The results of the comparative test show that there is no significant difference in the basic DM SPS between the first kuis and second kuis. This condition indicates that there is a need for innovation that can provide a better learning experience and can improve students' basic SPS.
\end{abstract}

Keywords: Degree of mastery, basic Natural Science, science process skills

\section{PENDAHULUAN}

Keterampilan proses sains (KPS) terdiri dari KPS dasar dan KPS terintegrasi [1]. KPS dasar mencakup keterampilan dalam mengobservasi, mengklasifikasi, mengukur, mengkomunikasi, memprediksi, dan menyimpulkan. KPS terintegrasi terdiri dari 6 indikator. KPS merupakan keterampilan fundamental yang diperlukan untuk menguasai sains [2], dan dapat membantu mahasiswa dalam menyelesaikan permasalahan yang dialami dalam kehidupan sehari-hari. Oleh karenanya KPS sangat penting bagi mahasiswa. Ditinjau dari aspek perkuliahan, produk umum yang menjadi tuntutan banyak mata kuliah adalah resume dan makalah. 
Untuk penyelesaiannya diperlukan keterampilan berkomunikasi secara tertulis. Keterampilan menyimpulkan juga diperlukan karena makalah memiliki sub-bagian kesimpulan. komunikasi secara lisan dibutuhkan pada saat pembelajaran di kelas, terutama pada sesi diskusi. Bagi mahasiswa yang memprogramkan skripsi, hampir seluruh indikator KPS diperlukan agar hasilnya baik dan dapat termanfaatkan. Hal ini mendorong peneliti untuk melakukan kajian, baik untuk melihat kondisi awal maupun memberikan treatment tertentu untuk meningkatkan KPS mahasiswa.

Kondisi KPS mahasiswa di Indonesia berdasarkan hasil penelitian sebelumnya bervariasi. [3] menemukan bahwa KPS mahasiswa di Universitas Jambi memiliki kategori baik di beberapa indikator seperti mengobservasi, mengklasifikasi, mengukur, merencanakan dan menganalisis percobaan, dan menyimpulkan. Beberapa indikator lainnya seperti mengkomunikasikan, serta memperoleh dan mengolah data masih berkategori tidak baik. [4] mengungkapkan bahwa KPS mahasiswa memiliki kategori terampil pada topik listrik magnet. [5] melaporkan sebanyak 33\% mahasiswa memiliki KPS level tinggi, 55\% sedang, dan $17 \%$ rendah. Di FKIP Tanjung Pura, KPS mahasiswa secara rata-rata tergolong rendah [6]. Berdasarkan jenjangnya, mahasiswa semester 7 memiliki rata-rata KPS paling tinggi dengan skor rata-rata 66.76. jenjang di bawahnya memiliki ratarata skor yang rendah yaitu 54.08 pada semester 5, 40.18 pada semester 3 , dan 34.51 pada semester 1 . [7] melaporkan temuan yang berbeda. KPS mahasiswa di UIN Antasari memiliki kategori yang cukup memuaskan. Indikator mengobservasi, mengklasifikasi, dan menafsirkan data bahkan berkategori baik.

$$
\text { Berdasarkan tahun publikasinya, }
$$
pengukuran KPS tersebut dilakukan sebelum pandemi Covid-19 di tetapkan di Indonesia. Sebelum masa pandemi, KPS mahasiswa ditingkatkan melalui pembelajaran tatap muka. Fasilitas yang digunakan dalam pembelajaran tatap muka ini dapat berupa model, media, alat peraga pembelajaran, maupun gabungannya. Di Indonesia, model pembelajaran yang diimplementasikan di antaranya problem based instruction [8], model praktikum problem solving laboratory [9], CCDSR teaching model [10], guided inquiry learning model [11], dan problem-based learning [12], Adapun beberapa media dan alat peraga yang menjadi fasilitas pembelajaran di antaranya local materials [13], modul praktikum mandiri [14], lembar kerja berbasis STEAM [15], Lembar Kerja Peserta Didik (LKPD) berbasis problem solving [16], dan buku petunjuk praktikum atau practicum guidebook [17]. Contoh gabungan adalah implementasi inquiry learning instruction model menggunakan simulasi komputer interaktif [18].

Dimasa pandemi, pembelajaran secara tatap muka tidak memungkinkan untuk dilaksanakan. Kondisi ini "memaksa" pembelajaran harus dilakukan secara nontatap muka langsung. Di Universitas Mataram, pembelajaran daring difasilitasi melalui SPADA (Sistem Pembelajaran Daring) Unram. Pembelajaran ini tergolong baru sehingga perlu dilakukan evaluasi terkait dampaknya terhadap hasil belajar. Di samping itu, walaupun secara nomenklatur termasuk noneksak, namun di kurikulum nasional untuk jenjang Sekolah Dasar (SD) menuntut penguasaan konsep IPA. Hal ini yang melatar belakangi pentingnya KPS - keterampilan fundamental yang diperlukan untuk menguasai sains [2] - dikuasai oleh mahasiswa Prodi PGSD di FKIP Universitas Mataram. Berdasarkan hal tersebut kami melakukan penelitian dengan tujuan untuk mengetahui potret KPS dasar mahasiswa. Hasil penelitian ini dapat memberikan informasi terkait tingkat KPS, serta indikator-indikator yang sudah dan belum dikuasai mahasiswa. Data ini akan menjadi pijakan yang bagus untuk menentukan fasilitas pembelajaran yang paling tepat agar mahasiswa dapat menguasai KPS dan mengimplementasikannya di kehidupan nyata.

\section{METODE PENELITIAN}

Penelitian ini merupakan penelitian deskriptif eksploratif yang dilakukan pada mahasiswa Prodi PGSD, FKIP Universitas Mataram selama bulan Agustus - November 2020. Sampel penelitian terdiri dari 35 mahasiswa semester 5 yang memprogramkan mata kuliah IAD. Sampel ditentukan secara purposive sampling berdasarkan fasilitas pembelajaran yang diberikan yaitu pure pembelajaran dengan memanfaatkan SPADA Unram. Sistem pembelajaran daring yang dimiliki oleh Universitas Mataram ini berbasis Moodle dan dilengkapi dengan fiture BigBlueButton (BBB) yang dapat dimanfaatkan untuk melakukan tatap muka secara virtual. Pada implementasinya, akun untuk mata kuliah IAD memiliki beberapa menu untuk memfasilitasi mahasiswa (Gambar 1). Menu-menu tersebut adalah folder bahan ajar, konferensi, forum diskusi, menu submit, menu chat dan kuis. Folder bahan ajar berisikan bahan ajar. Konferensi berfungsi sebagai media video cenference (vicon). Forum diskusi untuk diskusi secara firtual. Menu submit dapat dimanfaatkan mahasiswa untuk mengupload hasil kegiatan atau tugas. 


\section{Pengantar tentang $\underline{\mid A D}$}

Ruang Lingkup dan Pentingnya Mempelajari IAD

(ง)

Konferensi

Forum Dlskusi

Menu Submit Lembar Kerja

Cara Mempelajari IImu Alam

(

Konferensi

Forum Diskusi

Menu Submit Lembar Kerja

Menu Chat

Cara Mempelajari IImu Alam \#2

Forum Diskusi

Menu Submit Lembar Kerja

Quiz 1. IImu Alamiah Dasar

\section{Materi dan Energi}

Definisi dan Klasifikasi Materi

()

Konferensi

Forum Dlskusi

Menu Submit Lembar Kerja

Klasifikasi Materi berdasarkan Komponen Penyusun

( Konferensi

Menu submit pertanyaan

Menu submit resume

Perubahan Materi dan Konsep Energi

(๖) Konferensi

Menu Submit Pertanyaan

Menu Submit Resume

Quiz 2

Gambar 1. Menu-menu pada akun SPADA mata kuliah IAD

Variabel yang diukur adalah KPS dasar mahasiswa yang mencakup indikator mengamati (Mti), mengklasifikasi (Msi), mengukur (Mkr), mengkomunikasi (Mki), memprediksi (Mdi), dan menyimpulkan (Mkn). Data dikoleksi menggunakan instrumen tes melalui pelaksanaan kuis diakhir pembelajaran masing-masing topik. Instrumen tes terdiri dari 6 item soal yang disesuaikan dengan jumlah indikator KPS dasar yang mencakup keterampilan mengobservasi, mengklasifikasi, mengukur, mengkomunikasi, memprediksi, dan menyimpulkan. Kuis untuk mengukur KPS dasar mahasiswa dilakukan sebanyak dua kali yaitu pada topik Pengantar tentang IAD, dan Materi \& Energi. Waktu maksimal yang diberikan masing-masing kuis adalah 2 jam pelajaran atau setara dengan $2 \times 50$ menit sesuai dengan interval waktu pembelajaran tatap muka mata kuliah IAD dengan bobot 2 SKS. Penskoran jawaban siswa mengacu pada rubrik. Skor kemudian diolah menjadi nilai dengan rentang 0 100. Nilai yang menjadi dasar penentuan derajat penguasaan (DP) diinterpretasi menjadi kategori mengacu pada Pedoman Akademik Universitas Mataram (Tabel 1) agar mempermudah analisis data. Tabel 1. Pedoman interpretasi DP menjadi kategori. Analisis data dilakukan dengan menggunakan statistik deskriptif dan inferensial. Statistik deskriptif mencakup analisis DP, mean atau rata-rata, dan proporsi dalam bentuk persentase. Statistik inferensial yang digunakan adalah paired sample t-test pada taraf kepercayaan $95 \%$. Hipotesis yang diuji menggunakan t-test ini adalah (1) ada perbedaan rata-rata DP mahasiswa pada kuis 1 dan quis 2, (2) ada perbedaan rata-rata DP mahasiswa indikator mengobservasi pada kuis 1 dan quis 2, (3) ada perbedaan rata-rata DP mahasiswa indikator mengklasifikasi pada kuis 1 dan quis 2, (4) ada perbedaan rata-rata DP mahasiswa indikator mengukur pada kuis 1 dan quis 2, (5) ada perbedaan rata-rata DP mahasiswa indikator mengkomunikasi pada kuis 1 dan quis 2, (6) ada perbedaan rata-rata DP mahasiswa indikator memprediksi pada kuis 1 dan quis 2, dan (7) ada perbedaan rata-rata DP mahasiswa indikator menyimpulkan pada kuis 1 dan quis 2. Proses analisis menggunakan software Ms. Excel 2010 dan SPSS for windows versi 25.

Tabel 1. Pedoman interpretasi DP menjadi kategori

\begin{tabular}{cccc}
\hline No & Interval DP & Nilai & Kategori \\
\hline 1 & $\geq 80$ & A & Sangat baik \\
2 & $72-<80$ & B+ & Baik \\
3 & $65-<72$ & B & \\
4 & $60-<65$ & C + & Cukup \\
5 & $56-<60$ & C & \\
6 & $50-<56$ & D+ & Kurang \\
7 & $46-<50$ & D & Sangat kurang \\
8 & $<46$ & E & \\
\hline
\end{tabular}




\section{HASIL DAN PEMBAHASAN}

\section{Deskripsi KPS Dasar Mahasiswa}

Secara rata-rata, DP mahasiswa terhadap KPS dasar melalui implementasi SPADA Unram masih rendah. DP kuis $1(\mathrm{Q} 1)=37.88$, dan DP kuis 2 $(\mathrm{Q} 2)=34.46$ dari DP maksimal (DPm) sebesar 100 (Gambar 2). Berdasarkan interpretasinya, rata-rata KPS dasar mahasiswa berada pada kategori sangat kurang. Pada kuis 1 terdapat $11.43 \%$ mahasiswa memiliki KPS dasar dengan kategori baik dan cukup, $20 \%$ kategori kurang, dan yang paling tinggi proporsinya $(57.14 \%)$ berkategori sangat kurang (Tabel 2). Pada quis 2 KPS dasar mahasiswa lebih rendah. Proporsi dengan kategori baik dan cukup secara berturut-turut sebesar $2.86 \%$ dan $8.57 \%$, kategori kurang $22.86 \%$, dan kategori sangat kurang $65.71 \%$ (Tabel 2). Mahasiswa yang memiliki KPS dasar dengan kategori sangat baik tidak ada atau proporsinya $0.0 \%$.
Berdasarkan per indikator, rata-rata DP KPS dasar mahasiswa lebih tinggi pada kuis 1 dibandingkan dengan hasil pada kuis 2, kecuali indikator mengamati dan mengkomunikasi (Gambar 3). Dua indikator yaitu memprediksi dan menyimpulkan pada kuis 1 memiliki kategori baik dengan DP masing-masing 69.24 dan 74.48. Pada kuis dua hanya indikator mengamati yang memiliki kategori cukup dengan DP 58.76. indikator lain memiliki kategori sangat rendah dengan DP di bawah 46.00. Pada setiap indikator, baik untuk kuis 1 maupun kuis 2 selalu ada sejumlah mahasiswa yang memiliki kategori sangat rendah dengan skor perolehan 0 (Gambar 4). Pada kuis 1, proporsinya berkisar dari $5.71 \%$ pada indikator mengamati sampai dengan $31.43 \%$ pada indikator mengklasifikasi. Pada quis 2, proporsinya meningkat pada semua indikator kecuali pada keterampilan mengkomunikasi yang mengalami penurunan menjadi $25.71 \%$.

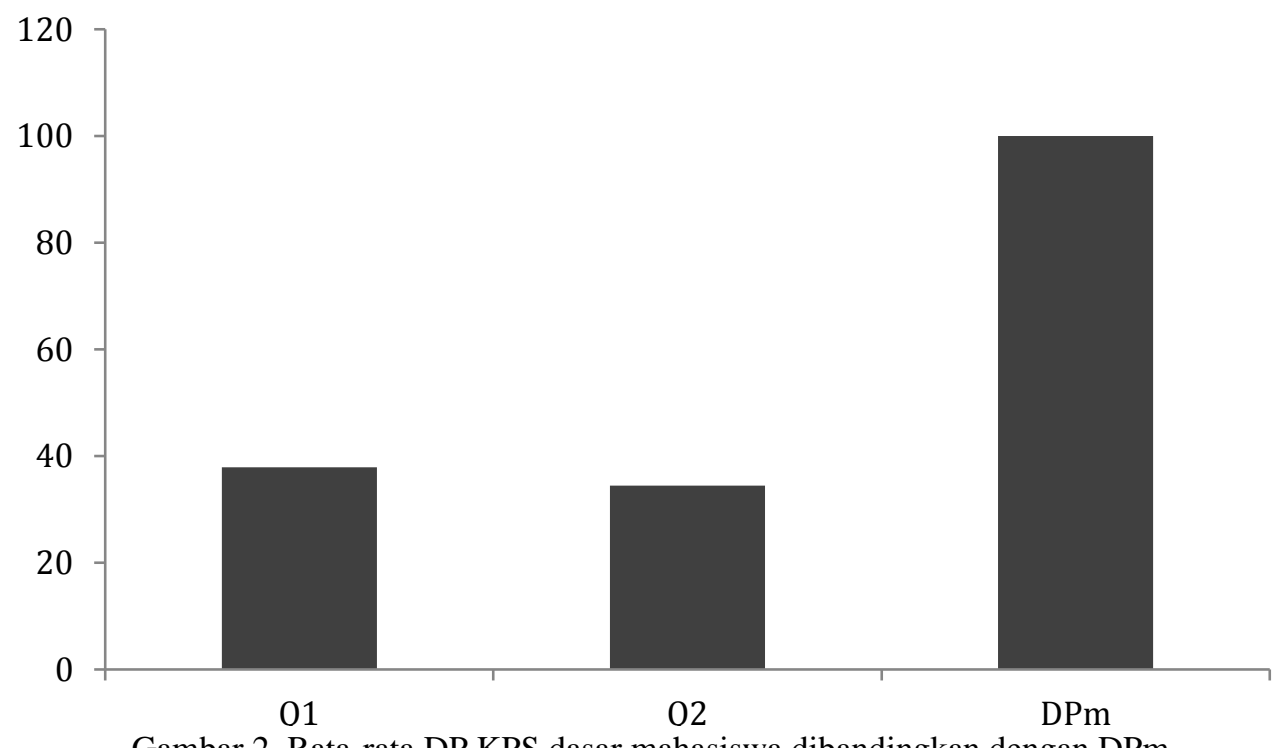

Gambar 2. Rata-rata DP KPS dasar mahasiswa dibandingkan dengan DPm

Tabel 2. Proporsi KPS dasar mahasiswa berdasarkan kategorinya

\begin{tabular}{|c|c|c|c|c|c|c|c|c|}
\hline \multirow{2}{*}{ No } & \multirow{2}{*}{\multicolumn{2}{|c|}{ Interval DP }} & \multirow{2}{*}{ Nilai } & \multirow{2}{*}{ Kategori } & \multicolumn{2}{|r|}{ Kuis 1} & \multicolumn{2}{|r|}{ Kuis 2} \\
\hline & & & & & $\mathrm{Ni}$ & Proporsi (\%) & $\mathrm{Ni}$ & Proporsi (\%) \\
\hline 1 & & $\geq 80$ & A & Sangat baik & 0 & 0 & 0 & 0 \\
\hline $\begin{array}{l}2 \\
3\end{array}$ & & $\begin{array}{l}-<80 \\
-<72\end{array}$ & $\begin{array}{c}\mathrm{B}+ \\
\mathrm{B}\end{array}$ & Baik & 3 & 8.57 & 1 & 2.86 \\
\hline $\begin{array}{l}4 \\
5\end{array}$ & $\begin{array}{l}60 \\
56\end{array}$ & $\begin{array}{l}-<65 \\
-\quad<60\end{array}$ & $\begin{array}{c}\mathrm{C}+ \\
\mathrm{C}\end{array}$ & Cukup & 4 & 11.43 & 3 & 8.57 \\
\hline $\begin{array}{l}6 \\
7\end{array}$ & $\begin{array}{l}50 \\
46\end{array}$ & $\begin{array}{l}-<56 \\
-<50\end{array}$ & $\begin{array}{c}\mathrm{D}+ \\
\mathrm{D}\end{array}$ & Kurang & 7 & 20 & 8 & 22.86 \\
\hline 8 & & $<46$ & $\mathrm{E}$ & Sangat kurang & 21 & 60 & 23 & 65.71 \\
\hline & & & mlah & & 35 & 100 & 35 & 100 \\
\hline
\end{tabular}




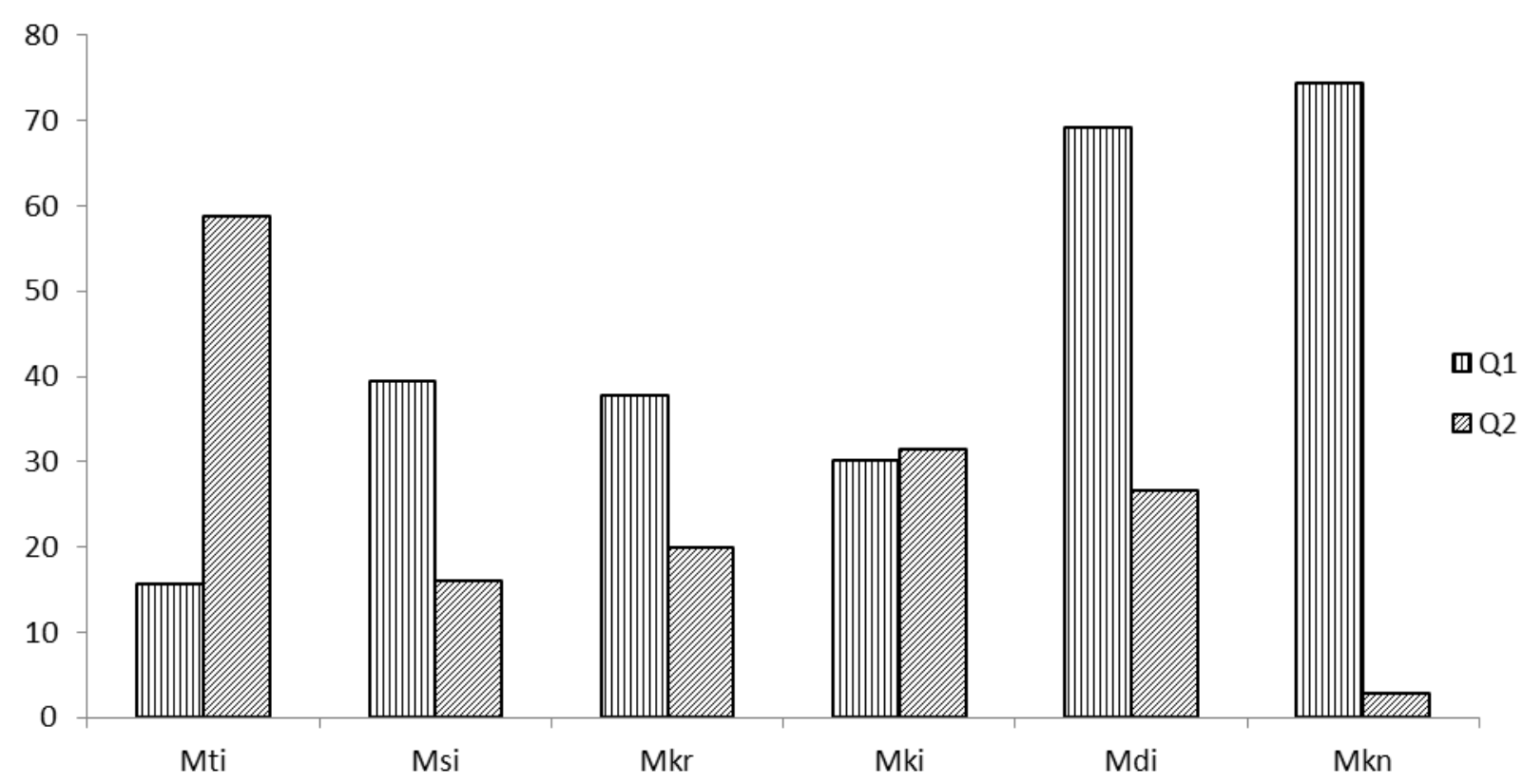

Gambar 3. Rata-rata DP KPS dasar pada kuis 1 dan kuis 2

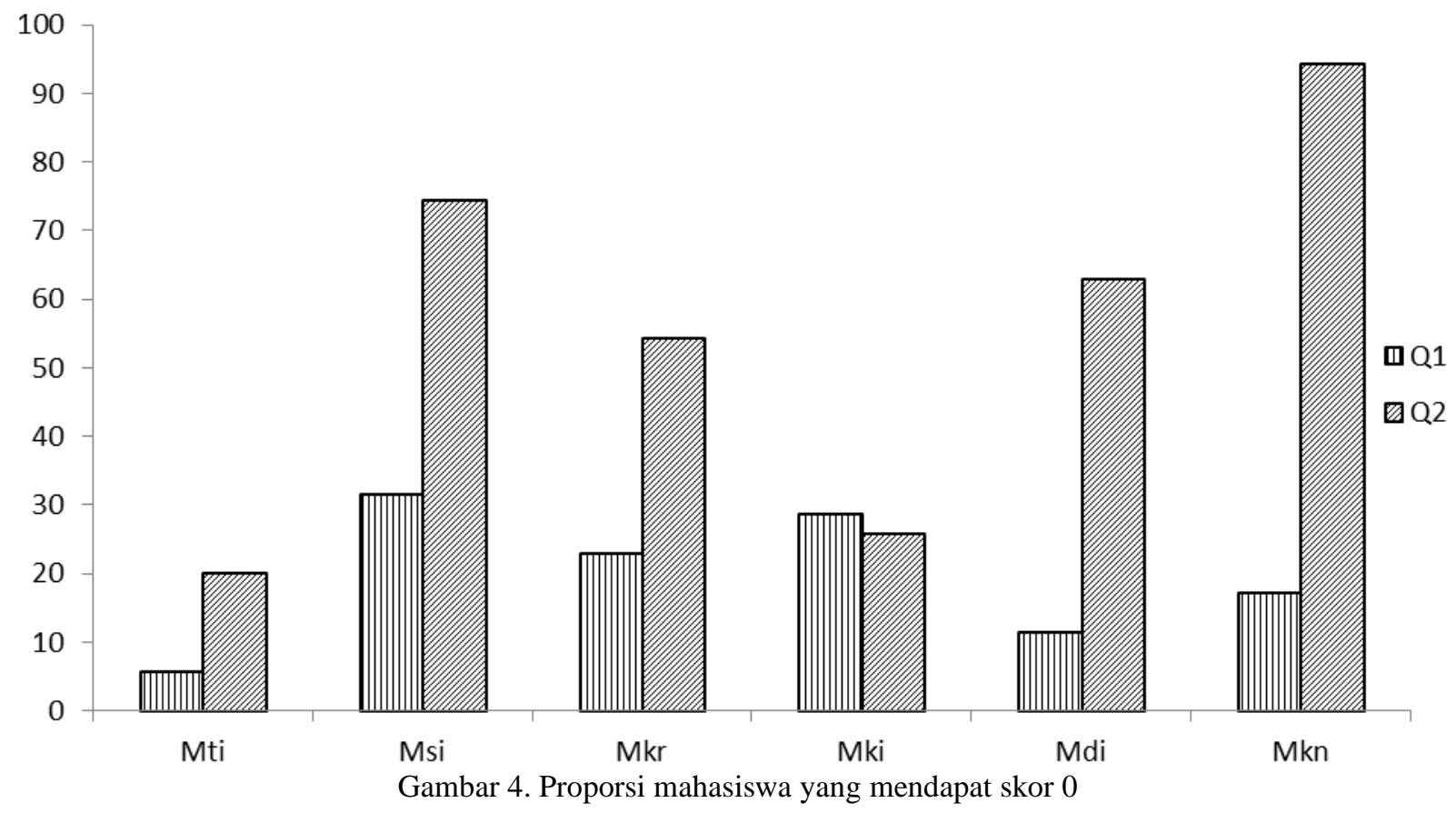

Pada quis 1 semua mahasiswa memiliki kategori sangat rendah untuk indikator mengamati, namun tidak semunya mendapat skor 0 karena sebanyak 94.29\% lainnya memiliki DP sebesar 16.67. Indikator lainnya lebih bervariasi karena pada indikator mengklasifikasi, mengukur, mengkomunikasi, memprediksi, dan menyimpulkan terdapat mahasiswa yang memiliki DP dengan kategori sangat baik. Proporsinya berbeda pada tiap indikator jika dibandingkan dengan kuis 2 (Gambar 5). Pada kuis 2 terdapat $42.86 \%$ mahasiswa memiliki
DP dengan kategori sangat baik pada indikator mengamati. Pada indikator mengukur dan menyimpulkan terdapat $5.71 \%$ mahasiswa memiliki DP dengan kategori sangat baik. Pada indikator memprediksi terdapat $22.86 \%$ mahasiswa memiliki DP dengan kategori sangat baik. Pada indikator mengklasifikasi kategori DP yang paling tinggi adalah baik dengan proporsi sebesar $14.29 \%$. proporsi lain seperti cukup, dan kurang bervariasi pada tiap indikator, demikian pula juka dibandingkan dengan hasil kuis 1 (Tabel 3). 


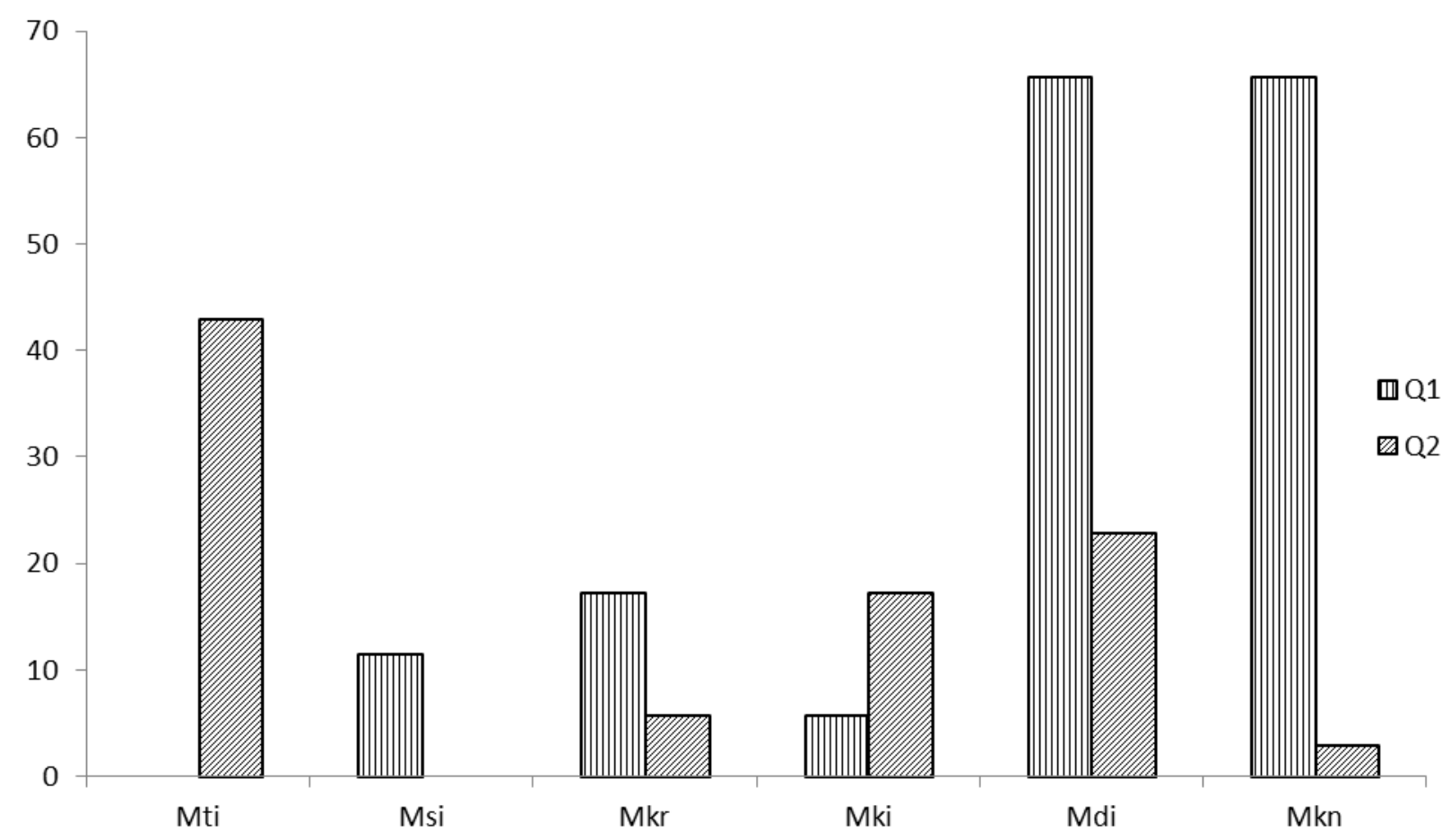

Gambar 5. Proporsi mahasiswa yang memiliki DP dengan kategori sangat baik

Tabel 3. Proporsi mahasiswa yang memiliki DP dengan kategori baik, cukup, dan kurang

\begin{tabular}{clccc}
\hline \multirow{2}{*}{ Kuis } & \multirow{2}{*}{ Indikator KPS Dasar } & \multicolumn{3}{c}{ Proporsi (\%) pada Tiap Kategori } \\
\cline { 2 - 4 } & Mengamati & Baik & Cukup & Rendah \\
\cline { 2 - 5 } 1 & Mengklasifikasi & 0 & 0 & 0 \\
& Mengukur & 20 & 2.86 & 0 \\
& Mengkomunikasi & 2.86 & 0 & 14.29 \\
& Memprediksi & 5.71 & 5.71 & 11.43 \\
& Menyimpulkan & 0 & 0 & 2.86 \\
\hline \multirow{2}{*}{2} & Mengamati & 5.71 & 0 & 5.71 \\
& Mengklasifikasi & 11.43 & 2.86 & 0 \\
& Mengukur & 14.29 & 0 & 0 \\
& Mengkomunikasi & 2.86 & 0 & 0 \\
\end{tabular}

\section{Uji Komparasi KPS Dasar Mahasiswa}

Kami menemukan korelasi terbesar pada tiap sampel berpasangan yang diuji adalah rata-rata DP kuis 1 dan kuis 2 dengan nilai korelasi 0.597 ( $p=$ $0.000<0.05$ ), dan sampel berpasangan yang memiliki korelasi paling kecil adalah rata-rata indikator mengklasifikasi dengan nilai korelasi 0.085 $(p=0.629>0.05)$. Sampel berpasangan lainnya memiliki nilai korelasi yang berkisar dari $0.110-$ 0.397 (Tabel 4). Uji t sampel berpasangan terhadap tujuh hipotesis penelitian yang diajukan menunjukkan lima hipetesis diterima dan 2 lainnya ditolak (Tabel 5). Rata-rata DP mahasiswa indikator mengobservasi, mengklasifikasi, mengukur, memprediksi dan menyimpulkan berbeda secara signifikan $(p<0.05)$ pada kuis 1 dan kuis 2 . Tidak terdapat perbedaan rata-rata DP mahasiswa pada kuis 1 dan kuis $2(p=0.274>0.05)$. Rata-rata DP mahasiswa indikator mengkomunikasi juga tidak berbeda secara signifikan $(p=0.839>0.05)$.

Keterampilan proses sains dasar mahasiswa sangat kurang dengan derajat penguasaan sebesar 37.88 pada kuis 1 dan 34.46 pada kuis 2 (Gambar 2). Ditinjau dari penelitian sebelumnya, fakta ini umum terjadi pada mahasiswa PGSD. [19] menemukan bahwa KPS mahasiswa PGSD di Uhamka berada pada kategori rendah. Rata-rata nilainya sebesar 46.46. keterampilan paling tinggi terdapat pada indikator menggunakan bahan dan alat, sedangkan keterampilan paling rendah adalah indikator mengkomunikasi. [20] melaporkan bahwa 
pemahaman mahasiswa terhadap KPS masih rendah, terutama pada indikator merumuskan hipotesis, mengidentifikasi variabel, membuat definisi operasional, menyajikan data hasil pengamatan dalam bentuk tabel, mengoleksi data, melakukan analisis data, dan keterampilan menyimpulkan. Hasil penelitian yang dilakukan oleh [21] terhadap mahasiswa PGSD FKIP Universitas Mataram semester ganjil 2015/2016 yang memprogramkan mata kuliah Konsep Dasar IPA menunjukkan perbedaan. Secara umum, KPS mahasiswa berkategori baik dengan rincian KPS dasar berkategori baik sedangkan KPS terintegrasi memiliki DP dengan kategori cukup.

Tabel 4. Korelasi sampel berpasangan

\begin{tabular}{lcccc}
\hline \multicolumn{5}{c}{ Paired Samples Correlations } \\
\hline Pair 1 & Kuis 1 \& Kuis 2 & N & Cerrelation & Sig. (2-tailed) \\
\hline Pair 2 & Mti 1 \& Mti 2 & 35 & 0.597 & 0.000 \\
Pair 3 & Msi 1 \& Msi 2 & 35 & 0.338 & 0.047 \\
Pair 4 & Mkr 1 \& Mkr 2 & 35 & 0.085 & 0.629 \\
Pair 5 & Mki 1 \& Mki 2 & 35 & 0.200 & 0.250 \\
Pair 6 & Mdi 1 \& Mdi 2 & 35 & 0.397 & 0.018 \\
Pair 7 & Mkn 1 \& Mkn 2 & 35 & 0.211 & 0.223 \\
\hline
\end{tabular}

Tabel 5. Hasil uji hipotesis

\begin{tabular}{clcc}
\hline No & Hipotesis Penelitian & $\mathrm{t}_{\text {hitung }}$ & $\begin{array}{c}\text { Signifikansi } \\
2 \text { tailed }\end{array}$ \\
\hline 1 & $\begin{array}{l}\text { ada perbedaan rata-rata DP mahasiswa pada kuis 1 dan quis 2 } \\
\text { ada perbedaan rata-rata DP mahasiswa indikator mengobservasi pada } \\
\text { kuis 1 dan quis 2 } \\
\text { ada perbedaan rata-rata DP mahasiswa indikator mengklasifikasi } \\
\text { pada kuis 1 dan quis 2 } \\
\text { ada perbedaan rata-rata DP mahasiswa indikator mengukur pada kuis }\end{array}$ & 1.113 & 0.274 \\
$\begin{array}{l}\text { 1 dan quis 2 } \\
\text { ada perbedaan rata-rata DP mahasiswa indikator menkomunikasi } \\
\text { pada kuis 1 dan quis 2 } \\
\text { ada perbedaan rata-rata DP mahasiswa indikator memprediksi pada } \\
\text { kuis 1 dan quis 2 } \\
\text { ada perbedaan rata-rata DP mahasiswa indikator menyimpulkan pada } \\
\text { kuis 1 dan quis 2 }\end{array}$ & -6.031 & 0.000 \\
& 5.641 & 0.003 \\
\hline
\end{tabular}

Terdapat perbedaan fasilitas pembelajaran yang diberikan kepada mahasiswa antara semester ganjil tahun 2015/2016 dan semserter ganjil tahun 2020/2021. Pertama karena kondisi sebelum pandemi dan dimasa pandemi akibat virus corona. Hal ini menunjukkan bahwa perubahan pembelajaran secara mendadak berdampak tidak bagus terhadap hasil belajar mahasiswa - KPS. Mahasiswa merasa pembelajaran tatap muka lebih efektif [22]. Mahasiswa membutuhkan adaptasi dan aklimatisasi agar dapat mengekspresikan performa yang bagus. Sedikit banyak, latar belakang seperti mahasiswa PGSD merupakan mahasiswa non-sains [23], pengetahuannya terhadap konsep sains relatif lebih rendah dibandingkan dengan mahasiswa sains. Selain itu, pembelajaran yang terbukti dapat meningkatkan KPS seperti problem based instruction [8], model praktikum problem solving laboratory [9], CCDSR teaching model [10], guided inquiry learning model [11], dan problem-based learning [12] memiliki kesamaan yaitu mahasiswa dilatih untuk memecahkan masalah sains. Ini sesuatu yang penting karena KPS erat kaitannya dengan hal tersebut. Kesamaan kedua adalah dilakukan secara tatap muka.

Pembelajaran melalui implementasi SPADA Unram tidak bisa dilakukan tatap muka walaupun secara virtual. Fiture BBB tidak berfungsi dengan baik akibat dari penggunaannya yang dilakukan pada banyak mata kuliah secara bersamaan. Kendala umum pada pembelajaran daring seperti jaringan tidak stabil dan ketersediaan kuota [24 - 27] membuat pengalaman belajar mahasiswa menjadi tidak optimal. Pembelajaran mata kuliah IAD ini juga tidak melatih mahasiswa untuk menyelesaikan permasalahan sains baik secara mandiri maupun proses guided. Melalui forum diskusi mahasiswa difasilitasi untuk mengungkapkan berbagai permasalahan sains dengan memposting rumusan masalah sains sesuai topik. Namun pemecahannya 
tidak memungkin dilakukan melalui scientific method yang banyak tahapannya menjadi indikator KPS. Ditinjau dari proses belajar mengajar, fokus mata kuliah IAD ini masih pada produk sains. Mahasiswa lebih dituntut untuk menguasai berbagai konsep, teori, prinsip, dan hukum terkait sains. Faktor lain yang menjadi penyebab rendahnya KPS dasar mahasiswa di antaranya rendahnya motivasi belajar mahasiswa, dan kecilnya bobot mata kuliah sains.

Motivasi belajar mahasiswa yang rendah dapat diamati dari banyaknya mahasiswa yang merasa tidak kuliah ketika difasilitasi melalui pembelajaran daring, dan hanya sebagian kecil yang aktif pada forum diskusi di SPADA Unram. Motivasi belajar merupakan faktor penting karena terbukti dapat meningkatkan hasil belajar sains mahasiswa PGSD [28]. Secara khusus, motivasi memiliki pengaruh yang signifikan terhadap kemampuan belajar IAD [29]. Motivasi belajar yang baik juga akan berdampak positif terhadap peningkatan KPS mahasiswa PGSD [30]. Adapun dari aspek bobot mata kuliah, pendidikan sains di Prodi PGSD FKIP Universitas Mataram hanya 3 SKS dari total 140-an SKS yang harus ditempuh oleh mahasiswa selama 8 semester atau lebih. Rendahnya bobot tersebut menyebabkan mahasiswa meluangkan waktu yang lebih sedikit untuk belajar sains, sehingga pengetahuannya menjadi relatif lebih rendah. Hal ini memberikan dampak yang tidak bagus karena hasil belajar IPA memiliki korelasi positif dan signifikan terhadap KPS mahasiswa PGSD [21]. Hal ini terbukti dari besarnya proporsi mahasiswa yang memiliki DP terhadap KPS dengan kategori rendah dan sangat rendah (Tabel 2).

Tabel 2 menunjukkan bahwa proporsi mahasiswa dengan KPS kategori rendah dan sangat rendah mencapai $80 \%$ pada kuis 1 dan $88.57 \%$ pada kuis 2. Walaupun demikian, mahasiswa memiliki DP dengan kategori cukup dan baik pada indikator mengobservasi, memprediksi dan menyimpukan (Gambar 3). Indikator lain masih berada pada kategori rendah dan sangat rendah terutama pada kuis kedua. Hal ini merupakan dampak dari tingginya proporsi dengan skor 0 pada indikatorindikator tersebut (Gambar 4). Di sisi lain, terdapat proporsi mahasiswa yang memiliki DP dengan kategori sangat baik pada setiap indikator, kecuali indikator mengobservasi pada kuis 1 dan indikator mengklasifikasi pada kuis 2 (Gambar 5). Proporsi kategori baik dan cukup terdapat pada beberapa indikator namun dengan persentase yang kecil (Tabel 3). Terdapatnya mahasiswa dengan KPS tersebut dapat dipahami karena mahasiswa pernah mendapat mata kuliah sains sebelumnya. Prodi PGSD unik karena termasuk prodi non-sains, namun mahasiswanya mendapat kuliah konsep sains. Berdasarkan hal hal ini, mahasiswa mata kuliah IAD memiliki sejumlah kompetensi sains. Seperti diungkapkan oleh [31] bahwa kemampuan awal memiliki hubungan yang signifikan dengan KPS mahasiswa.

Selain kemampuan awal, faktor lain yang juga berperan terhadap pencapaian terhadap KPS mahasiswa adalah topik sains. Namun ini hanya berlaku pada tingkat indikator karena secara rata-rata terdapat korelasi yang siginifikan dan positif antara kuis 1 dan kuis 2 (Tabel 4). Hasil uji komparasi juga mendukung pernyataan tersebut di mana tidak terdapat perbedaan yang signifikan antara kuis 1 dan kuis 2. Indikator-indikator yang DP mahasiswanya tergantung topik di antaranya keterampilan mengobservasi, mengukur, memprediksi, dan menyimpulkan. Fenomena ini sama seperti saintis yang hanya expert di bidang tertentu. Ahli biologi expert di bidang biologi, sedangkan ahli fisika expert di bidang fisika, demikian pula dengan ahli kimia yang expert di bidang kimia. Di tiap bidang tersebut pun keahlian saintis terspesialisasi. Misalnya bidang biologi dibagi menjadi cabang-cabang ilmu seperti ekologi, taksonomi, herpetologi, botani, zoologi, dan lain-lain yang tiap cabang tersebut memiliki saintisnya masing-masing. Saintis ekologi tentunya lebih terampil dalam mengobservasi, mengukur, memprediksi, dan menyimpulkan fenomenafenomena alam yang terkait ekologi dibandingkan dengan saintis dari cabang-cabang ilmu biologi yang lain.

Relevansinya dengan hasil penelitian ini adalah ada perbedaan tingkat kompetensi pada mahasiswa terkait topik yang digunakan untuk pembelajaran. Setidaknya terdapat 3 bentuk perbedaan yaitu (1) kompotensi tiap mahasiswa terhadap Topik 1, (2) kompotensi tiap mahasiswa terhadap Topik 2, dan (3) kompotensi tiap mahasiswa terhadap Topik 1 dibandingkan dengan Topik 2. Tiga aspek ini yang berdampak terhadap adanya perbedaan DP KPS pada tingkat indikator yang signifikan pada hasil kuis 1 dan kuis 2 . Banyak penulis seperti [10 - 12] menyebutkan topik pembelajaran yang digunakan untuk menginformasikan bahwa hasil penelitiannya terhadap KPS mahasiswa berlaku pada topik tersebut, dan belum tentu berlaku pada topik yang lain. Perbedaan tingkat kompetensi tergantung pada daya adaptasi dan aklimatisasi terhadap perubahan dari pembelajaran luring ke daring, dan literasi ICT mahasiswa. Pada tataran implementasinya, terdapat beberapa kendala pembelajaran daring seperti jaringan yang unstable, dan ketersediaan kuota internet. Hal ini juga terjadi pada pembelajaran IAD. Pada setiap pembelajaran berlangsung, selalu ada mahasiswa yang memberikan konfirmasi terkait masalah tersebut.

Ditinjau dari persepsinya, daya adaptasi dan aklimatisasi mahasiswa PGSD, FKIP Universitas 
Mataram terhadap pembelajaran daring masih rendah. Hal ini tampak dari menurunnya intensitas interaksi secara vertikal dengan dosen sebagai fasilitator dan interaksi secara horizontal dengan sesama mahasiswa apabila dibandingkan dengan pembelajaran secara tatap muka sebelum pandemi Covid-19 [32]. Terkonfirmasi juga bahwa mahasiswa lebih suka belajar secara tatap muka, dan materi yang disampikan oleh dosen masih banyak yang belum dipahami atau hanya sedikit dari sejumlah tujuan pembelajaran yang dikuasai. Faktor kejenuhan dalam melakukan pembelajaran online juga berdampak pada tidak optimalnya proses belajar mengajar, dan penguasaan mahasiswa terhadap tujuan-tujuan pembelajaran kurang memuaskan [33]. Selain itu, pembelajaran daring juga memberikan efek yang negatif terhadap mahasiswa. Efek negatif ini di antaranya (1) secara umum mahasiswa masih mengalami kebingungan terkait pembelajaran daring, (2) mahasiswa cenderung pasif, kurang produktif dan kreatif, (3) adanya tumpukan konsep yang kurang berfaedah, dan (4) rasa jenuh atau bosan membuat mahasiswa stres [34].

\section{KESIMPULAN}

Keterampilan proses sains mahasiswa berada pada kategori sangat rendah. Walaupun demikian, terdapat beberapa indikator di mana mahasiswa memiliki derajat penguasaan dengan kategori cukup, baik, dan sangat baik.

\section{DAFTAR PUSTAKA}

[1] Can, B., Yildiz-Demirtas, V., \& Altun, E. (2017). The effect of project- based science education programme on scientific process skills and conceptions of Kindergarten students. Journal of Baltic Science Education, 16(3), 395413.

[2] Prayitno, B. A., Corebima, D., Susilo, H., Zubaidah, S., \& Ramli, M. (2015). Closing the science process skills GAP between students with high and low level academic achievement. Journal of Baltic Science Education, 16(2), 266277.

[3] Darmaji Darmaji, Kurniawan, D. A., Parasdila, H., \& Irdianti. (2018). Deskripsi keterampilan proses sains mahasiswa pada materi termodinamika. Berkala Ilmiah Pendidikan Fisika, 6(3), 345-353.

[4] Yolanda, Y. (2019). Profil keterampilan proses sains (KPS) mahasiswa fisika pada materi listrik magnet. JIPFRI: Jurnal Inovasi Pendidikan Fisika Dan Riset Ilmiah, 3(2), 70-78. https://doi.org/10.30599/jipfri.v3i2.533

[5] Hasyim, F. (2018). Mengukur kemampuan berpikir analitis dan keterampilan proses sains mahasiswa calon guru fisika STKIP Al Hikmah
Surabaya. JIPVA (Jurnal Pendidikan IPA Veteran), 2(1), 80-89.

[6] Hamdani. (2017). Deskripsi keterampilan proses sains mahasiswa calon guru fisika. Jurnal Pendidikan Matematika Dan IPA, 8(1), 43-51.

[7] Khairunnisa, Ita, \& Istiqomah. (2019). Keterampilan proses sains (KPS) mahasiswa Tadris Biologi pada Mata Kuliah Biologi Umum. BIO-INOVED : Jurnal Biologi-Inovasi Pendidikan, 1(2), 58-65.

[8] Malik, A. (2015). Model pembelajaran problem based instruction untuk meningkatkan penguasaan konsep dan keterampilan proses sains mahasiswa. JPPPF - Jurnal Penelitian \& Pengembangan Pendidikan Fisika, 1(1), 9-16. https://doi.org/10.21009/1.01102

[9] Malik, A., Handayani, W., \& Nuraini, R. (2015). Model praktikum problem solving laboratory untuk meningkatkan keterampilan proses sains mahasiswa. In A. H. A. Dwi Irwanto, Fiki Taufik Akbar (Ed.), Simposium Nasional Inovasi dan Pembelajaran Sains (pp. 193-196). Program Studi Magister Pengajaran Fisika FMIPA ITB.

[10] Limatahu, I., Wasis, Sutoyo, S., \& Prahani, B. K. (2018). Development of CCDSR teaching model to improve science process skills of preservice physics teachers. Journal of Baltic Science Education, 17(5), 812-827.

[11] Malau, S. M., Motlan, Sirait, M., \& Lubis, R. H. (2019). The effect of guided inquiry learning model and creativity on students science process skills. Journal of Transformative Education and Educational Leadership, 1(2), 29-37.

[12] Duda, H. J., Herawati Susilo, \& Newcombe, P. (2019). Enhancing different ethnicity science process skills: problem-based learning through practicum and authentic assessment. International Journal of Instruction, 12(1), 1207-1222.

[13] Prajoko, S., Amin, M., Rohman, F., \& Gipayana, M. (2016). The effect of local materials usage for science practicum on students' science process skills. Educational Research International, 5(4), 1-10.

[14]Rohman, F., \& Lusiyana, A. (2018). Pengembangan modul praktikum mandiri sebagai asesmen keterampilan proses sains dan keterampilan sosial mahasiswa. JIPFRI: Jurnal Inovasi Pendidikan Fisika Dan Riset Ilmiah, 1(2), 47-56.

[15] Patresia, I., Silitonga, M., \& Ginting, A. (2020). Developing biology student s, worksheet based on STEAM to empower science process skills. JPBI (Jurnal Pendidikan Biologi Indonesia), 6(1), 147-156. https://doi.org/10.2229/jpbi.v6i1. 10225 
[16] Ubaidillah, M. (2016). Pengembangan LKPD fisika berbasis problem solving untuk meningkatkan keterampilan proses sains dan keterampilan berpikir tingkat tinggi. Jurnal EduFisika, 01(02), 9-20.

[17] Darmaji Darmaji, Kurniawan, D. A., Suryani, A., \& Lestari, A. (2018). An identification of physics pre-service teachers' science process skills through science process skills -based practicum guidebook. Jurnal Ilmiah Pendidikan Fisika Al-BiRuNi, 07(2), 239-245.

[18] Supriyatman, S., \& Sukarno, S. (2014). Improving science process skills (SPS) science concepts mastery (SCM) prospective student teachers through inquiry learning instruction model by using interactive computer simulation. International Journal of Science and Research (IJSR), 3(2), 6-9.

[19] Sari, P. M., \& Zulfadewina. (2018). Profile of science process skill mastery from pre-service elementary school teacher. Jurnal Inovasi Pendidikan Dasar, 3(2), 65-72.

[20] Julianto, Wasis, \& Agustini, R. (2018). Profil sikap terhadap sains, keterampilan proses sains, dan kreativitas mahasiswa Jurusan PGSD FIP UNESA di Mata Kuliah Konsep Dasar IPA. Seminar Nasional Pendidikan, 197-202.

[21] Artayasa, I. P., Susilo, H., Lestari, U., \& Indriwati, S. E. (2017). Profil keterampilan proses sains dan hubungannya dengan hasil belajar sains mahasiswa Pendidikan Guru Sekolah Dasar. In T. P. T. P. dan P. D. U. N. Malang (Ed.), Seminar Nasional Teknologi Pembelajaran dan Pendidikan Dasar (pp. 706714). Pascasarjana Teknologi Pembelajaran dan Pendidikan Dasar Universitas Negeri Malang. http://pasca.um.ac.id/conferences/index.php/snte pnpdas/article/view/933.

[22]Zamista, A. A., Rahmi, H., Sellyana, A., \& Desriyati, W. (2020). Persepsi mahasiswa terhadap pembelajaran dalam jaringan untuk mata kuliah kalkulus. Jurnal THEOREMS (The Original Research of Mathematics), 5(1), 41-48.

[23] Deta, U. A., Prakoso, I., Agustina, P. Z. R., Fadillah, R. N., Lestari, N. A., Yantidewi, M., Admoko, S., Zainuddin, A., Nurlailiyah, A., \& Prahani, B. K. (2020). Science process skills profile of non-science undergraduate student in Universitas Negeri Surabaya. Journal of Physics: Conf. Series.

[24] Hutauruk, A., \& Sidabutar, R. (2020). Kendala pembelajaran daring selama masa pandemi di kalangan mahasiswa pendidikan matematika: Kajian kualiatatif deskriptif. SEPREN: Journal of Mathematics Education and Applied, 02(01), 45-51.

[25] Ita. (2020). Hasil belajar dan respon mahasiswa terhadap pelaksanaan pembelajaran daring pada mata kuliah biologi umum. Konferensi Nasional Pendidikan, 143-147.

[26] Legowo, Y. A. S. (2020). Kesiapan dan kendala pembelajaran berbasis projek melalui media daring pada mahasiswa Universitas Darul Ulum Islamic Centre Sudirman Guppi. Jurnal Wawasan Pengembangan Pendidikan, 02(02), 62-68.

[27] Nainggolan, J., Pardede, S., \& Butar-butar, I. (2020). Survei kendala Dosen Fakultas Keguruan dan Ilmu Pendidikan Universitas HKBP Nommensen dalam pelaksanaan perkuliahan online. Jurnal Suluh Pendidikan, $8(2), 1-8$.

[28] Syofyan, H., \& Yuliati. (2017). Pengaruh gaya belajar dan motivasi berprestasi terhadap hasil belajar IPA mahasiswa PGSD Universitas Esa Unggul. Seminar Nasional Multi Disiplin Ilmu, 779-788.

[29] Permana, A. D. I. (2016). Pengaruh gaya belajar dan motivasi belajar mahasiswa terhadap kemampuan belajar ilmu alamiah dasar. Jurnal Formatif, 6(3), 276-283.

[30] Kelana, J. B., Muftianti, A., \& Samsudin, A. (2020). Pemanfaatan media pembelajaran dalam meningkatkan keterampilan proses sains dan motivasi belajar mahasiswa PGSD. Jurnal Ilmiah P2M STKIP Siliwangi, 7(1), 48-54.

[31] Amnah, S., \& Idris, T. (2016). Hubungan indeks prestasi kumulatif dengan keterampilan proses sains mahasiswa Pendidikan Biologi FKIP UIR t.a 2013/2014. Jurnal Pelita Pendidikan, 4(1), 137-144.

[32] Rahmatih, A. N., \& Fauzi, A. (2020). Persepsi mahasiswa calon guru sekolah dasar dalam menanggapi perkuliahan secara daring selama masa Covid-19. MODELING: Jurnal Program Studi PGMI, 7(2), 143-153.

[33] Indrawati, B. (2020). Tantangan dan peluang Pendidikan Tinggi dalam masa pandemi Covid19. Jurnal Kajian Ilmiah, 1(1), 39-48.

[34] Argaheni, N. B. (2020). A systematic review: The impact of online lectures during the covid19 pandemic against Indonesian students. PLACENTUM: Jurnal Ilmiah Kesehatan Dan Aplikasinya, 8(2), 99-109. 